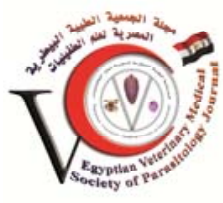

Original Article

\title{
A Preliminary Survey on Eimeria species infecting Chicken in Gharbia Governorate, Mid-Delta of Egypt
}

Abdelrazek Y Desouky', Khaled Sultan', Khaled I Al Ekhnawy², Noha I Ammar', 2

'Department of Parasitology, Faculty of Veterinary Medicine, Kafr El Sheikh University, Egypt ${ }^{2}$ Animal Health Research Institute, Dokki, Giza, Egypt

\begin{abstract}
:
The present study conducted to investigate prevalence of Eimeria species in chickens in Gharbia governorate, Mid-Delta, Egypt. From a total of 800 samples examined, 614 (76.75\%) were positive for Eimeria oocysts. According to chicken breeds, white broiler was the most infected 371/614 (46.37\%), then Balady chickens 124/614 (15.5\%), then Saso chickens $86 / 614(10.75 \%)$ and lastly layers $33 / 614(4.12 \%)$. Regarding age, the most affected ages was in-between 31-40 days old 255/614 (31.83\%), followed by 21-30 days old 90/614 (11.24\%). All districts were found infected with one or more of Eimeria species, the most affected districts were El-Mahalla El-Kubra and Kotoor 95/614 (11. 875\% for each district), while ElSanta was the lowest 29/614 (3.625\%). Seven species of Eimeria viz., E. tenella, E. acervulina, E. mitis, E. praecox, E. necatrix, E. burnetti and E. maxima were recorded with prevalence of 14.5, $13.875,13.375,11.25,9.5,8.5$ and $5.75 \%$ respectively. Eimeria tenella was found the most predominant species in the study area. This study highlight the high incidence of Eimeria species infecting chicken in Egypt and tell new and updated results that might help in controlling such infection.
\end{abstract}

Key words: Eimeria, Chicken, Coccidia, Prevalence, Egypt

\section{INTRODUCTION}

Chicken coccidiosis is one of the most important protozoan diseases worldwide. It is responsible for much economic losses in the poultry industry. It caused by infection with one or more of the Eimeria species infecting chickens (McDougald and Reid, 1997; McDouglad, 2003). The protozoan parasites of the genus Eimeria species multiply in the intestinal tract and cause tissue damage, with resulting interruption of feeding and digestive processes or nutrient absorption, dehydration, blood loss, loss of skin pigmentation and increased susceptibility to other disease agents (Williams, 1996). Nine species of Eimeria may infect chickens. The species important in broiler production include Eimeria tenella, E. maxima, E. acervulina, and E. mivati; the species important in breeder and egg- layers are E. brunetti and E. necatrix. Eimeria tenella and $E$. necatrix are the most pathogenic species. $E$. acervulina, E. maxima and E. mivati are common and slightly or moderately pathogenic; $E$. brunetti is uncommon but pathogenic when it does occur. E. mitis, $E$. praecox and $E$. hagani are relatively non-pathogenic species (Reid and Long, 1979; Conway and McKenzie, 1991). Coccidiosis is one of the most important diseases in commercial poultry production in Egypt. But, there is scanty and controversy information on the occurrence of the different Eimeria species in spite of many research papers carried on coccidiosis in Egypt, as Khilfa, (1982), Ahmed et al. (2003), Abu-Akkada and Awad, (2010), AlGawad et al. (2012) and Gadelhaq et al. (2015), they all study the coccidiosis in different Governorates of Egypt and Coccidia still cause severe economic losses in poultry industry. So, the present study aims are detection and estimation of different Eimeria species infection of different breeds and ages of chicken in Gharbiah governorate, to give new and updated information which may help in control of such infection.

\section{MATERIALS AND METHODS}

Study area and design: Gharbia governorate is one of the Mid-Delta governorates, north to Cairo $\left(30.881^{\circ} \mathrm{N} 31.06^{\circ}\right.$ E). A cross-sectional survey designed including the 8 districts of the governorate (i.e. El-Mahalla El-Kubra, Kafr El-Zyat, Samannoud, Tanta, Zifta, El-Santa, Kotoor and Bassyoun) to find the prevalence of different Eimeria species involved in chicken coccidiosis and factors associated with this infection.

Samples: From August 2013 till the end of December 2014 a total of 800 fecal samples (100 samples from each district) were collected from broilers and layers chickens of 
different breeds, ages and management practices. Each sample labeled individually; preserved after collection in separate clean polyethylene bags then in plastic containers, kept in refrigerator at $4^{\circ} \mathrm{C}$ with $2.5 \%$ Potassium dichromate and transferred to the lab of Department of Parasitology, Faculty of Veterinary Medicine, Kafrelsheikh University for further examination.

\section{Laboratory examination:}

Samples processed for morphological examination by concentration floatation technique. The processed samples were examined with calibrated light microscope fitted with scale-measure ocular lens according to Conway and McKenzie (2007) to determine the oocysts shape and index (Length/Width). Eimeria-positive samples were further processed by McMaster-chamber method according to Conway and McKenzie (1991) to determine the Eimeria oocyst count. Also, Eimeria-positive samples were sporulated in $2.5 \%$ potassium dichromate according to Davies et al. (1963) and Wash et al. (1985). After sporulation, oocyst count and checking of the morphology, shape index were determined again to identify the Eimeria species. Oocysts of different Eimeria spp. images were captured using digital camera, scale bar was determined using method of Otify (2012) and software ImageJ 1.49v.

Statistical analysis: The statistical analysis was done by using the statistical package Microsoft Excel software. Data were compiled and represented in tables.

\section{RESULTS}

Out of a total 800 examined samples; 614 (76.75\%) were positive for Eimeria oocysts. According to chicken breeds, white broiler was the most infected $371 / 614$ (46.37\%), then Balady chickens $124 / 614$ (15.5\%), then Saso chickens 86/614 (10.75\%) and lastly layers 33/614 (4.12\%). Regarding age (Table 1), the most affected ages was inbetween 31-40 days old 255/614 (31.83\%), followed by 21 30 days old $90 / 614$ (11.24\%). All districts were found to be infected with one or more of Eimeria species (Table 2), the most affected districts were El-Mahalla El-Kubra and Kotoor 95/614 (11. 875\% for each district), while El-Santa was the lowest 29/614 (3.625\%). Seven species of Eimeria

Table 1: Prevalence of different Eimeria infection detected among different ages of examined chicken

\begin{tabular}{|c|c|c|c|c|c|c|}
\hline \multirow{2}{*}{$\begin{array}{c}\text { Age range } \\
\text { (day) }\end{array}$} & \multicolumn{2}{|c|}{ Positive samples } & \multicolumn{2}{|c|}{ Negative samples } & \multicolumn{2}{|c|}{ Total } \\
\hline & Number & $\%$ from total & Number & $\%$ from total & Number & $\%$ from total \\
\hline $10-20$ & 40 & 5 & 10 & 1.25 & 50 & 6.25 \\
\hline $21-30$ & 90 & 11.24 & 20 & 2.50 & 110 & 13.75 \\
\hline $31-40$ & 255 & 31.83 & 44 & 5.50 & 299 & 37.38 \\
\hline $41-50$ & 80 & 10 & 11 & 1.39 & 91 & 11.38 \\
\hline $51-60$ & 28 & 3.44 & 20 & 2.50 & 48 & 6 \\
\hline $61-70$ & 25 & 3.21 & 20 & 2.50 & 45 & 5.62 \\
\hline $71-80$ & 25 & 3.21 & 17 & 2.12 & 42 & 5.25 \\
\hline $81-90$ & 50 & 6.20 & 20 & 2.50 & 70 & 8.75 \\
\hline$>90$ & 21 & 2.61 & 24 & 3 & 45 & 5.62 \\
\hline Total & 614 & 76.74 & 186 & 23.26 & 800 & 100 \\
\hline
\end{tabular}

$\mathrm{Chi}^{2}=33.45$, Significant at $\mathrm{p}<0.01$

Table 2: Prevalence of Eimeria detected in different districts in Gharbia Governorate, Egypt

\begin{tabular}{lcccc}
\hline District & Positive & \% from total & Negative & \% from total \\
\hline El-Santa & 29 & 3.625 & 71 & 8.875 \\
Kafr El-Zyat & 93 & 11.625 & 7 & 0.875 \\
Kotoor & 95 & 11.875 & 5 & 0.625 \\
Tanta & 81 & 10.125 & 19 & 2.375 \\
Bassyoun & 96 & 12 & 4 & 0.5 \\
Zifta & 49 & 6.125 & 51 & 6.375 \\
El-Mahalla El-Kubra & 95 & 11.875 & 5 & 0.625 \\
Samannoud & 76 & 9.5 & 24 & 3 \\
Total & 614 & 76.75 & 186 & 23.25 \\
\hline
\end{tabular}


Table 3: Prevalence, oocyst length, oocyst width and shape index of different Eimeria species detected from examined samples

\begin{tabular}{|c|c|c|c|c|c|c|}
\hline \multirow[t]{2}{*}{ Eimeria species } & \multirow[t]{2}{*}{ Positive } & \multirow{2}{*}{$\begin{array}{l}\% \text { from } \\
\text { positive }\end{array}$} & \multirow{2}{*}{$\begin{array}{c}\% \text { from } \\
\text { total }\end{array}$} & $\begin{array}{c}\text { Oocyst Length in } \\
\mu \mathrm{m}\end{array}$ & $\begin{array}{c}\text { Oocyst Width in } \\
\mu \mathrm{m}\end{array}$ & $\begin{array}{c}\text { Shape Index } \\
\text { (L/W) }\end{array}$ \\
\hline & & & & Mean \pm SE & Mean \pm SE & Mean \pm SE \\
\hline E. preacox & 90 & 14.65 & 11.25 & $22.35 \pm 0.38$ & $17.39 \pm 0.30$ & $1.29 \pm 0.00$ \\
\hline E. tenella & 116 & 18.89 & 14.5 & $19.93 \pm 0.28$ & $17.01 \pm 0.19$ & $1.17 \pm 0.01$ \\
\hline E. maxima & 46 & 7.49 & 5.75 & $22.74 \pm 0.72$ & $15.59 \pm 0.53$ & $1.46 \pm 0.01$ \\
\hline E. brunetti & 68 & 11.07 & 8.5 & $22.73 \pm 0.55$ & $16.99 \pm 0.43$ & $1.34 \pm 0.00$ \\
\hline E. necatrix & 76 & 12.37 & 9.5 & $20.45 \pm 0.57$ & $18.25 \pm 0.49$ & $1.12 \pm 0.00$ \\
\hline E. mitis & 107 & 17.42 & 13.375 & $17.46 \pm 0.41$ & $17.03 \pm 0.34$ & $1.02 \pm 0.01$ \\
\hline E. acervulina & 111 & 18.07 & 13.875 & $22.71 \pm 0.49$ & $18.47 \pm 0.39$ & $1.23 \pm 0.00$ \\
\hline
\end{tabular}

$\mathrm{SE}=$ Standard Error, significantly different at $\mathrm{P}<0.01$

Table 4: Prevalence of different Eimeria species detected in examined chickens of each district of Gharbia Governorate, Egypt

\begin{tabular}{|c|c|c|c|c|c|c|c|c|}
\hline & $\begin{array}{c}E . \\
\text { preacox }\end{array}$ & $\begin{array}{c}E . \\
\text { tenella }\end{array}$ & $\begin{array}{c}E . \\
\text { maxima }\end{array}$ & $\begin{array}{c}E . \\
\text { brunetti }\end{array}$ & $\begin{array}{c}E . \\
\text { necatrix }\end{array}$ & $\begin{array}{c}E . \\
\text { mitis }\end{array}$ & $\begin{array}{c}E . \\
\text { acervulina }\end{array}$ & Total \\
\hline El-Santa & 2 & 7 & 0 & 3 & 5 & 6 & 6 & 29 \\
\hline Kafr El-Zyat & 13 & 7 & 10 & 9 & 16 & 22 & 16 & 93 \\
\hline Kotoor & 18 & 24 & 5 & 16 & 12 & 11 & 9 & 95 \\
\hline Tanta & 12 & 6 & 5 & 8 & 15 & 24 & 11 & 81 \\
\hline Bassyoun & 18 & 19 & 10 & 7 & 9 & 17 & 16 & 96 \\
\hline Zifta & 5 & 13 & 3 & 8 & 4 & 4 & 12 & 49 \\
\hline El-Mahalla El-Kubra & 8 & 20 & 11 & 5 & 10 & 16 & 25 & 95 \\
\hline Samannoud & 14 & 20 & 2 & 12 & 5 & 7 & 16 & 76 \\
\hline Total & 90 & 116 & 46 & 68 & 76 & 107 & 111 & 614 \\
\hline
\end{tabular}

viz., E. tenella, E. acervulina, E. mitis, E. praecox, E. necatrix, E. burnetti and $E$. maxima recorded with prevalence of $14.5,13.875,13.375,11.25,9.5,8.5$ and $5.75 \%$ respectively (Figure 1 and Table 3). Eimeria tenella was the most predominant species in the study area. The length, width and shape index (length/ width) for each Eimeria species oocysts was also recorded (Table 3). Each district has more the one Eimeria species (Table 4).

\section{Discussion}

Chicken coccidiosis is one the most important economic diseases in Egypt and worldwide. In the current study, the incidence of Eimeria-infection was $72.75 \%$ which go in line with results of Khilfa (1982) who mentioned that the incidence of coccidiosis among chicken in Egypt with different ages were $84.24 \%$ and Abu-Akkada and Awad (2010) result that detected the infection rate as $20-100 \%$ and mortality is $20-60 \%$ with severe reduction in body gain and feed efficiency. But in the other hand, the results of the current work disagree with those of Ahmed et al., (2003) who reported that the prevalence was $43.9 \%$ in
Egypt, Al-Gawad et al. (2012) who examined balady breed chicken in (Cairo, Giza, El-Gharbia, El-Behiera, Kafr ElSheikh, El-Sharqiyah, Ismailia, Qina and Aswan) the incidence was $21.24 \%$ and recorded Cairo and Giza regions showed highest incidence of infection (37.16\%) followed by Eastern delta regions (36.30\%). While, the lowest incidence was recorded Western delta regions (7.32\%), also our results was higher than that obtained by El-Gaos (2014) who stated that the incidence of coccidiosis in broiler chickens in Dakahlia governorate was $45 \%$. In comparing our results with those in other areas of the world, our results on coccidiosis incidence agrees with Gari et al. (2008), But, our results are higher than reported before by Lundén et al. (2000) recorded that $19.3 \%$ incidence in layer farms in Sweden at the age ranged between 19-32 weeks and 25.8\% . Ashenafi et al. (2004) indicated that $25.8 \%$ of chicken were infected with Eimeria spp. in Ethiopia and Naphade (2013) in India the incidence of coccidiosis was $9.18 \%$, in broiler chicken. The variation in-between the incidence of Eimeria in the current study and other researcher's studies is understandable. Generally speaking, the incidence and 


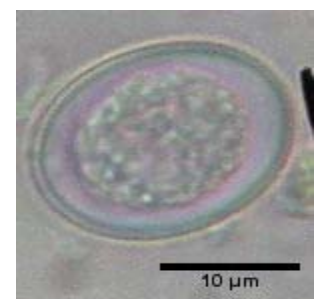

A

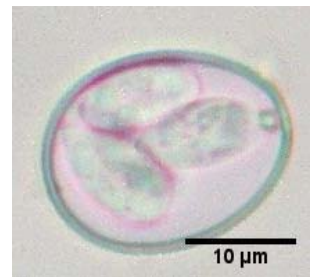

E

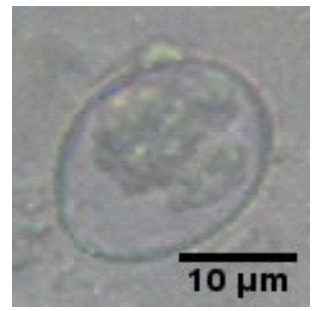

I

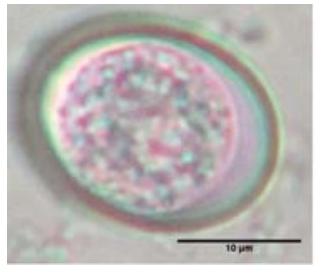

M

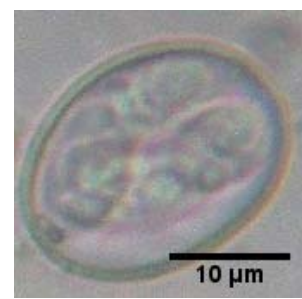

B

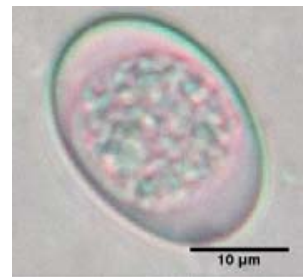

F

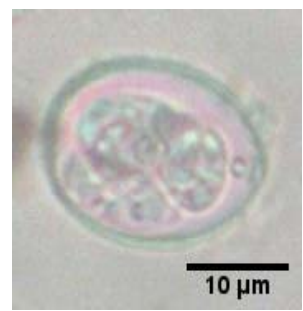

J

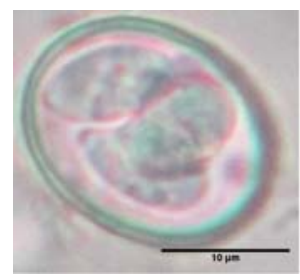

N

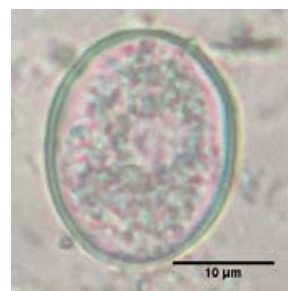

C

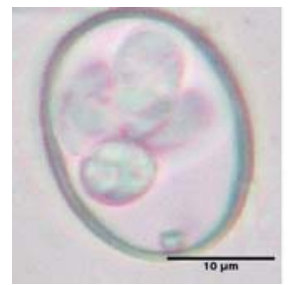

G

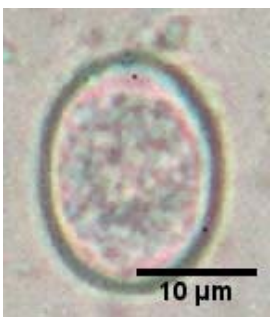

K

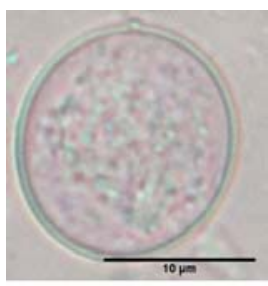

0

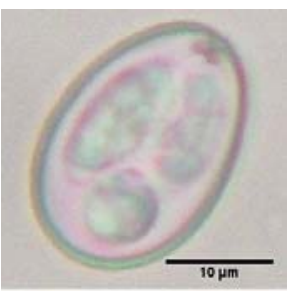

D

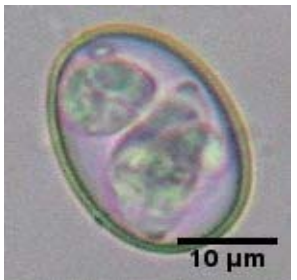

H

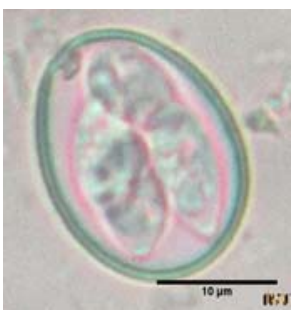

L

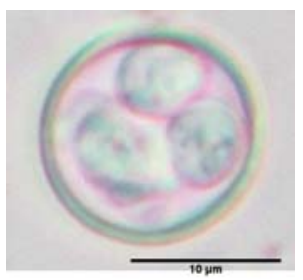

P

Figure 1: Oocysts of different Eimeria spp. isolated from chickens in the current study: E. necatrix (A: Non-sporulated, B: Sporulated); E. maxima (C: Non-sporulated, D\& E: Sporulated); E. acervulina (F: Non-sporulated, G\& H: Sporulated); E. brunette (I: Non-Sporulated, J: Sporulated); E. tenella (K: Non-sporulated, L: Sporulated); E. praecox (M: Non-sporulated, N: Sporulated) and E. mitis (O: Non-sporulated, P: Sporulated).

prevalence of coccidiosis or Eimeria-infection is much variant from geographical locality to another and within the same country due to different factors such as, chicken breed, age at sampling, mangemental ways, season, other disease conditions..etc; all these factors and more may affect directly or indirectly to the detected incidence of Eimeria. In the present study seven Eimeria species were identified and their incidence was recorded as follows: $E$. tenella (18.90\%), E. acervulina (18.07\%), E. necatrix $(12.38 \%)$, E. maxima (7.49\%), E. mitis (17.42\%), E. brunette (11.07\%) and E. praecox (14.66\%). So, the highest incidence was recorded in infection with E.tenella (18.9\%), while the lowest was E.maxima (7.49\%). These results go in line with the results of other researchers from Egypt as Abu Elezz (1994) who stated that E. tenella was the most prevalent species in balady chickens; AbuAkkada and Awad (2010) they recorded E. tenella as the most detected species in Egypt with incidence ranged inbetween $20-100 \%$ and more recent work of Gadelhaq et al. (2015) mentioned that the same 7 Eimeria recorded in baldi chickens in Beni Suef province, Upper Egypt. But our results on number and incidence of Eimeria species infecting chickens disagree with the results of researchers in Egypt like Khilfa (1982) who stated the incidence of different species was as follow: E. necatrix 30-90\%, $E$. tenella $20-100 \%$, E. acervulina $10-80 \%$, E. mitis $10-40 \%$, E. preacox 5-10\%, E. hagani 5\%, and E. maxima 4-10\%; Ahmed et al. (2003) and El Behairy (2005) as they reported absence of $E$. brunetti and E. praecox among the examined balady chicks; Kutkat et al. (2009) detected 
only six Eimeria species from four Egyptian Governorates (Qalubeia, Sharkeia, Fayoum and Giza) which were $E$. necatrix, E. acervulina, E. praecox, E. maxima, E. mitis and $E$. tenella and Al-Gawad et al. (2012) examined balady breed chicken in (Cairo, Giza, El-Gharbia, ElBehiera, Kafr El- Sheikh, El- Sharqiyah, Ismailia, Qina and Aswan) and recorded E. necatrix $58.27 \%$ E. tenella $25.82 \%$, E. acervulina $19.20 \%$ E. mitis $10.59 \%$ and $E$. maxima 4.66\%; Also, in comparison of our results on number and incidence Eimeria species infecting chickens disagree with other researchers in other parts of the world like Edgar and Seibold (1964) in Alabama State, USA, found that all flocks had been infected with $E$. acervulina $100 \%$, E. tenella $94 \%$, E. necatrix $65 \%$ and $E$. brunetti 12\%, Williams (1996) stated six species occurring together. E. acervulina $100 \%$, E. mitis $82 \%$, E. tenella $77 \%$, E. maxima $73 \%$, E. preacox $45 \%$ and E. brunetti $27 \%$ in commercially-reared chickens in France; Ashenafi et al. (2004) the recorded Eimeria species were E. necatrix, E. acervulina, E. maxima and $E$. tenella in scavenging indigenous chickens in central Ethiopia; Lobago et al. (2005) found prevalent species were E. brunetti 45.3\%, $E$. tenella $40 \%$, E. acervulina $9.7 \%$, E. necatrix $4.1 \%$ in Kombolcha poultry farms, Ethiopia; Haug et al (2008) agreed with our results in recording the presence of $E$. preacox in $9.8 \%$ of broiler chicken in Norway; Lee et al. (2010) who determined that 7 Eimeria species were detected in all the positive farms by PCR. E. acervulina $87 \%$ and $E$. tenella $62.5 \%$ were the most prevalent, followed by $E$. brunette $59.3 \%$ and $E$. praecox 37.5 on Korean chicken farms; Jatau et al. (2012) found 7 Eimeria species were identified as E. maxima $58.6 \%$, E. acervulina $47.1 \%$, E. mitis $30.0 \%$, E. brunetti $28.6 \%$ E. tenella $22.9 \%$ E. preacox $8.6 \%$ in Zaria, Nigeria. While Thenmozhi et al. (2014) used COCCIMORPH identification software and revealed the presence of E. acervulina (79.49\%), E. tenella (72.88\%), E. mitis (50.62\%), E. maxima (35.52\%) and $E$. necatrix $(10.83 \%)$ in the farms screened. E. brunette was not recorded in any of the farms screened in Chennai, Tamil Nadu, India. Again, the variation in-between the number and incidence of Eimeria species detected in the current study and other researchers studies is understandable. It can be attributed to several factors such as the overlapping in-between the dimensions and shape of different Eimeria species oocysts; in fact the previously mentioned cause is the main reason that may explain the differences in-between the researchers. Other factors may include the skills of the examiner, using different techniques in identification (e.g. COCCIMORPH and $\mathrm{PCR}$ ), age at sampling, sampling procedures, chicken breed, poor poultry management where there is overcrowding, leaking water troughs and accumulation of feces are factors that contributed to the high prevalence rate. About morphology and dimension of different Eimeria spp. oocysts, our present study indicated that length, width and shape index of Eimeria oocysts as follow: E. preacox was 22.35-17.39 $\mu \mathrm{m}-1.29$, E. tenella 19.93-17.01 $\mu \mathrm{m}$-1.17, E. maxima 22.47-15.95 $\mu \mathrm{m}$-1.46, $E$. brunetti 22.73-16.99 $\mu \mathrm{m}-1.34$, E. necatrix 20.45-18.25 $\mu \mathrm{m}$ -1.12 , E. mitis 17.46-17.03 $\mu \mathrm{m}-1.02$ and $E$. acervulina 22.71-18.47 $\mu \mathrm{m}-1.23$. These results agree with that of in Egypt Nowar (2007) recorded E. acervulina 20-16 $\mu \mathrm{m}, E$. necatrix 20-18 $\mu \mathrm{m}$, and E. mitis 16-13 $\mu \mathrm{m}$. Also, these results nearly go in line with Amer et al. (2010) who calculated the index of 4 isolate species as $E$. tenella 1.14 , E. necatrix 1.19, E. acervulina 1.25 and E. preacox 1.23 . Our results also detect the $E$. necatrix length as $20.45 \mu \mathrm{m}$ and width as $18.25 \mu \mathrm{m}$ and index as 1.12 which go in line with the results of Jadhav (2011) Who detect E. necatrix oocysts in broiler chicken in India length as 13.2-22.5 $\mu \mathrm{m}$ (16.2) width 11-18.7 $\mu \mathrm{m}$ (15.7) and index 102-1.4(1.3); AlGawad et al. (2012) from Egypt detect 5 Eimeria species in balady chicken which agree with our oocysts identification as E. mitis 17.8-14.1-1.26, E. acervulina 18.214.1-1.29, E. necatrix 20.1-16.9-1.19, E. tenella 21.3-17.91.19 and $E$. maxima 29.9-23.8-1.25. The incidence between different breed in Gharbia governorate, was in White broiler $46.37 \%$, Saso broiler $10.75 \%$, Balady broiler $15.5 \%$ and Layer $4.12 \%$. The incidence of Eimeria species infection detected in the current study in-between different chicken ages in Gharbia governorate was the highest in 30-40 days (31.83\%), 21-30 days (11.24\%), 4150 days (10\%) and the lowest incidence in age over 90 days (2.61\%). These results agree with that of Nawar (2007) who examined broiler chicken only in Dakahlia governorate found the highest infection was in age of 25 days $40 \%$, followed by 35 days $29.21 \%$ and 15 day $20.8 \%$; Al-Gawad et al. (2012) found balady breed chicken in Egypt and find all examined samples of age less than 21 days was completely free. Also these results nearly go in line with that of El-Gaos (2014) who studied that broiler chickens in Dakahlia governorate and find the age incidence were $25.6 \%$ for $1-14$ days, $65.6 \%$ for $15-28$ days and $43.7 \%$ for $29-42$ days .In other parts of the world, our 
results are in line with the results of Lunden et al. (2000) found the incidence of coccidiosis in layer farms in Sweden at the age of $19-32$ weeks was $19.3 \%$. But these results disagree with that of Jatau et al. (2012) in Nigeria; they found Eimeria infection as $44.3 \%$ in layer, $37.1 \%$ in broiler and $18.6 \%$ in indigenous chicken; Olanrewaju and Agbor (2014) detected the infection rate among Broiler birds less than 3 months was $60 \%$, layers $66.67 \%$, cockerel $70 \%$ and local birds $67 \%$. In birds of 3 months and above, cockerel has the highest prevalence rate of $100 \%$, followed by broiler and layer which have the prevalent rate of $80 \%$. However, local birds have the lowest prevalent rate (50\%) in Nigeria. In conclusion, the present study demonstrate high incidence of Eimeria spp. infection in mid-Delta of Egypt and provide updated information on such infection which might help in control of it. Further investigations are encouraged.

\section{Acknowledgments}

Authors wish to express their thanks to all Veterinarians and farm owners who help during collection of the study samples. Also, they are grateful to staff members of Parasitology Department, Faculty of Veterinary Medicine, Kafrelsheikh University for their sincere cooperation during the study.

\section{Conflict of interest}

The authors declare that they have no conflict of interest. This research is a part of N. Amaar study to get M.V.Sc. "Parasitology".

\section{REFERENCES}

Abu-Akkada, S.S., Awad, A.M. (2010): Isolation, propagation, identification and comparative pathogenicity of five Egyptian field strains of Eimeria tenella from broiler chickens in five different provinces in Egypt. Research in Veterinary Science, 92 (1):92-95.

Abu Elezz, N.T. (1994): Immunological studies on Eimeria species in fowls. Ph. D. Thesis, Fac. Vet. Med. Cairo Univ.

Ahmed, N.E., Negm Eldin, M.M., El Akabawy. L.M., El Medawy, R.S. (2003): Incidences of some protozoan parasites in Birds. Kafr El-sheikh Vet. Med. J. 1(1):235-251. Al-Gawad, A.A., Mahdy, O.A., El-Massry, A.A.N., Al-Aziz, M.S.A. (2012): Studies on Coccidia of Egyptian Balady Breed Chickens. Life Sci. J. 9(3):568-576.

Amer, M.M., Awaad, M.H.H., Rabab, M. ElKhateeb, Nadia, M.T.N. Abu-Elezz, et al. (2010): Isolation and Identification of Eimeria from Field Coccidiosis in Chickens. J. Amer. Sci. 6(10):1107-1114.

Ashenafi, H., Tedessa, S., Medhin, G., Tibbo, M (2004):
Study on coccidiosis of chickens in central Ethiopia. Trop. Anim. Health Prod. 36(7): 693-701.

Conway, D.P., Mckenzie, M.E. (1991): Poultry coccidiosis diagnostic and testing procedures. $2^{\text {nd }} E d$., Chapter 2, PP: 17-36.

Conway, D.P., McKenzie, M.E. (2007): Poultry coccidiosis, Diagnostic and testing procedures. $3^{\text {th }}$ Ed., Blackwell publishing.

Davies, S.F.M., Joyner, L.P., Kendall, S.B. (1963): Coccidiosis. Oliver and Boyd Publisher, Edinburgh, UK.

Edgar, S.A., Seibold, C.T. (1964): A new coccidium of chickens, Eimeria mivati sp .n. (protozoa: Eimeriidae) with details of its life history. J. Parasitol. 50:193-209.

El-Behairy, A.M. (2005): Immuno-characterization of some Eimeria spp. Infecting chicken in Egypt. Master Thesis, Fac. Vet. Med. Cairo Univ.

El-Goas, M.I.A. (2014): Studies on coccidial sensitivity to certain drugs. Ph.D. Thesis, Fac. vet. Med, Mansoura Univ.

Gadelhaq, S.M., Arafa, W.A., Aboelhadid, S.M. (2015): Molecular Characterization of Eimeria Species Naturally Infecting Egyptian Baladi Chickens. Iran. J. Parasitol. 10 (1):87-95.

Gari G., Tilahun G., Dorchies P. (2008): Study on poultry coccidiosis in Tiyo district, Azone, Ethiopia. Int. J. Poult. Sci. 7:251-256.

Haug, A., Gjevre, A.G., Skjerve, E., Kaldhusdal, M. A. (2008): Survey of the Economic Impact of Subclinical Eimeria Infections in Broiler Chickens in Norway. Avian Pathology, 37; 333-341.

Jadhav B.N, Nikam S.V., Bhamre S.N., Jaid E.L. (2011): Study of Eimeria necatrix in broiler chicken from Aurangabad District of Maharashtra state India. International Multidisciplinary Research Journal, 1(11):1112

Jatau, I.D., Suliman, N.H., Musa, I.W., Lawai, A.I., Okuban Joisah, 0.O., Magaji, Y. (2012): Prevalence of coccidia infection and preponderance Eimeria species in free range indigenous and intensively managed exotic chickens during hot-wet season in Zaria, Nigeria. Asian Journal of Poultry Science, 6:79-88.

Khalifa, D.G. (1982): Further studies on coccidiosis in poultry. Ph.D. Thesis, Fac. Vet. Med., Cairo University.

Kutkat, M.A., Shalaby, H.A., EL Khateeb, R.M., Abu ELezz, N.M., Zayed, A.A., Abdel Razik, A.B., et al. (2009): Molecular diagnosis of Eimeria and Clostridia in simultaneously infected chickens. Global Veterinaria, 3 (1), 26-31.

Lee, B.H., Kim, W.H., Jeong, J., Yoo, J., Kwon, Y.K., Jung, B.Y., et al. (2010): Prevalence and cross-immunity of Eimeria species on Korean chicken farms. J. Vet. Med. Sci. 72:985-989.

Lobago, F., Worku, N., Wossene, A. (2005): Study on coccidiosis in Kombolcha poultry farms, Ethiopia. Trop. Anim. Health Prod.; 37(3): 245-251.

Lunden, A., Thebo, P., Gunnarsson S., Hooshmian-Rad, P., Tauson, R., Uggla, A. (2000): Eimeria infection in litterbased, high stocking density systems for loose-housed 
laying hens in Sweden. Brit. Poult. Sci., 41: 440-447.

McDougald, L.R., Reid, W.M. (1997): Coccidiosis. In: Calnek BW, Barnes HJ, Beard, CW, McDougald LR., Saif MY, editors. Diseases of poultry. Iowa State University Press, Ames, IA; PP: 865-883.

McDougald, L.R. (2003): Diseases of Poultry. Protozoal Infections. In: Saif Y.M., Barnes H.J., Glisson J.R., Fadly A.M., McDougald L.R., Swayne D.E., editors. lowa State University Press; PP: 973-1023.

Naphade, S.T. (2013): Studies on incidence of infection of the disease coccidiosis in broiler chickens from in and around Aurangabad city. Ind. J. Sci. Res. and Tech., 1 (3):39 $-43$.

Nawar, M. H.A.N. (2007): Field evaluation of methods of coccidia infection control in some poultry farms in Dakahlia governorate. Ph.D. Thesis, Fac. Vet. Med., Kafrelsheikh University.

Olanrewaju, C.A., Agbor, R.Y. (2014): Prevalence of Coccidiosis Among Poultry Birds Slaughtered At Gwagwalada Main Market, Abuja, FCT, Nigeria. The International Journal Of Engineering And Science; 3(1) 4145.
Otify, Y.Z. (2012): Movable computer ruler (MCR): A new method for measuring the size of Toxoplasma gondii cysts, tachyzoites and other selected parasites. Experimental Parasitology, 130: 1-5.

Reid, W.M., Long, P.L. (1979): Diagnostic Chart for 9 Species of Fowl Coccidia. Georgia Agricultural Experiment Station Research Report, 5-24.

Thenmozhi V., Veerakumari L., and Raman M. (2014): Preliminary Genetic Diversity Study on Different Isolates of Eimeria tenella from South India. International Journal of Advanced Veterinary Science and Technology .Volume 3, Issue 1, pp. 114-118, Article ID Sci-211 ISSN 2320-3595.

Wash, C.D., Duszynski, D.W., Yates, T.L. (1985): Eimerians from different karyotypes of the Japanese wood mouse (Apodemus spp.), with descriptions of two new species and a redescription of Eimeria montgomeryae Lewis and Ball, 1983. Journal of Parasitology 71: 808-814.

Williams, R.B. (1996): A survey of Eimeria species in commercially-reared chickens in France during. Avian Pathology, 25:113-130. 